\title{
Margaret McCartney: Cancer strategy should be led by evidence
}

\author{
Margaret McCartney general practitioner, Glasgow
}

Harpal Kumar, chief executive of the charity Cancer Research UK (CRUK), is to chair the new Cancer Strategy Taskforce,

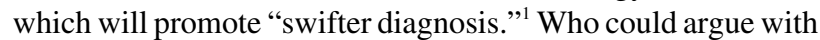
that? Well, I have some concerns.

GPs are in an invidious position. Few symptoms, conceivably, could never represent cancer. Referring every patient with any symptom for further tests would do enormous harm to the over-investigated population - and to the people whose worrying symptoms are investigated less swiftly because of the waiting list that GPs have created.

New draft guidelines from the National Institute for Health and Care Excellence (NICE) recommend lowering the bar so that patients are referred for further investigations when their calculated risk of cancer reaches $3 \%{ }^{2}$ NICE also proposes less sensitive tests. So, for example, it recommends a serum cancer antigen 125 test for women with persistent abdominal distension, but ultrasound examination for ovarian cancer is more accurate. ${ }^{3}$

NICE also suggests cheaper tests to assess the risk of bowel cancer in symptomatic patients, such as faecal occult blood in stool-yet we have accumulated evidence that a negative test is not reliable enough to exclude a serious underlying cause. ${ }^{4}$ Are less good tests going to cancel out any benefit of a lowered investigative threshold?

Cancer is not the only condition worth diagnosing, and tests with high rates of false negatives will lead to uncertainty. Cost effectiveness does not justify anxiety in patients or doctors. General practice is a smorgasbord of unexplained symptoms, illness, cultural expectations, rituals, slender positive predictive values, red flags that usually don't predict cancer well, and frequent sub-threshold aches and pains that are probably nothing sinister and rarely something to be concerned about.

CRUK is "not waiting" on the taskforce, however, but is pressing ahead with various work, including "projects" on instigating self referrals for diagnostic tests, as well as its current public "awareness" campaign, Be Clear on Cancer. ${ }^{5}$ (This advises people who have had indigestion most days for three weeks to see their GP. Pilot studies showed $10 \%$ more referrals than in control areas but no statistically significant increase in diagnosing upper gastric cancers.)
CRUK has recommended that women should have breast screening, ${ }^{6}$ and it wants to increase the uptake of bowel cancer screening. ${ }^{7}$ Ethically, however, doctors should promote informed choice because screening can do harm. CRUK is also responsible for a recent fundraising campaign urging people to "battle cancer," to the dismay of many patients. ${ }^{8}$

We need a task force whose examination of early diagnosis is led by the fair use of evidence, grounded in an understanding of the highly complex world of general practice, and which is capable of recognising ineffectiveness and the harm resulting from hype.

Competing interests: I have read and understood the BMJ policy on declaration of interests and declare the following interests: I'm an NHS GP partner, with income partly dependent on Quality and Outcomes Framework points. I'm a part time undergraduate tutor at the University of Glasgow. I've written two books and earn from broadcast and written freelance journalism. I'm an unpaid patron of Healthwatch. I make a monthly donation to Keep Our NHS Public. I'm a member of Medact. I'm occasionally paid for time, travel, and accommodation to give talks or have locum fees paid to allow me to give talks but never for any drug or public relations company. I was elected to the national council of the Royal College of General Practitioners in 2013 and am chair of its standing group on overdiagnosis. I have invested a small amount of money in a social enterprise, Who Made Your Pants?

The BMS's readers can buy Margaret's new book, Living with Dying, for $£ 7.99$ (RRP £11.99) including UK delivery from www.pinterandmartin. com with checkout code BMJ799.

Provenance and peer review: Commissioned; not externally peer reviewed.

Kumar H. My role as independent chair of the Cancer Strategy Taskforce. Cancer Research UK science blog .11 Jan 2015. http://scienceblog.cancerresearchuk.org/2015/01/11/myrole-as-independent-chair-of-the-cancer-strategy-taskforce/.

2 National Institute for Health and Care Excellence. Suspected cancer: recognition and management of suspected cancer in children, young people and adults. Draft NICE guideline for consultation. November 2014. www.nice.org.uk/guidance/gid-cgwave0618 documents/suspected-cancer-update-draft-nice-guideline2.

3 National Institute for Health and Care Excellence. Ovarian cancer: the recognition and initial management of ovarian cancer. December 2010. www.nice.org.uk/resource/ madro7h6snmt6gjm24dd6mh6la.

4 Tate JJ, Northway J, Royle GT, Taylor I. Faecal occult blood testing in symptomatic patients: comparison of three tests. Br J Surg 1990;77:523-6. 
5 Ohuma E, Power E, Moffat J, Formby S, Ormiston-Smith N. Improving the diagnosis of oesophago-gastric cancers: findings from the seven Be Clear on Cancer pilots. Poster 95. www.ncin.org.uk/news_and_events/conferences/2013_posters.

6 Cancer Research UK. What the breast screening review means. www.cancerresearchuk. org/about-cancer/cancers-in-general/cancer-questions/what-the-breast-screening-reviewmeans.

7 Cancer Research UK. Our policy on bowel cancer screening. www.cancerresearchuk. org/about-us/we-develop-policy/our-policy-on-early-diagnosis/our-policy-on-bowel-cancerscreening.
8 McCartney M. The fight is on: military metaphors for cancer may harm patients. Rapid responses. BMJ 2014;349:g5155. www.bmj.com/content/349/bmj.g5155/rapid-responses.

Cite this as: BMJ 2015;350:h735

(c) BMJ Publishing Group Ltd 2015 